\title{
Slot Machine Response Frequency Predicts Pathological Gambling
}

\author{
Jakob Linnet ${ }^{1,2,3,4,5}$, Kristine Rømer Thomsen ${ }^{2,6}$, Arne Møller ${ }^{2,3} \&$ Mette Buhl Callesen ${ }^{2,3}$ \\ ${ }^{1}$ Research Clinic on Gambling Disorders, Aarhus University Hospital \\ ${ }^{2}$ Center of Functionally Integrative Neuroscience, Aarhus University \\ ${ }^{3}$ Nuclear Medicine Department \& PET Center, Aarhus University Hospital \\ ${ }^{4}$ Division on Addiction, Cambridge Health Alliance \\ ${ }^{5}$ Harvard Medical School \\ ${ }^{6}$ Department of Psychiatry, University of Oxford \\ Correspondance: Jakob Linnet, Research Clinic on Gambling Disorders, Aarhus University Hospital, Aarhus \\ University, Nørrebrogade 44, Building 30, DK-8000 Aarhus C, Denmark. Tel: 45-7-846-1698. E-mail: \\ jlinnet@mac.com
}

Received: August 7, $2012 \quad$ Accepted: November 26, $2012 \quad$ Online Published: February 21, 2013

doi:10.5539/ijps.v5n1p121 URL: http://dx.doi.org/10.5539/ijps.v5n1p121

This study was supported by the Danish Agency for Science, Technology and Innovation grant number 2049-03-0002 and 2102-05-0011, and the Ministry of Health grant number 1001326. The authors declare that they have no competing financial interests.

\begin{abstract}
Slot machines are among the most addictive forms of gambling, and pathological gambling slot machine players represent the largest group of treatment seekers, accounting for 35\% to $93 \%$ of the population. Pathological gambling sufferers have significantly higher response frequency (games / time) on slot machines compared with non-problem gamblers, which may suggest increased reinforcement of the gambling behavior in pathological gambling. However, to date it is unknown whether or not the increased response frequency in pathological gambling is associated with symptom severity of the disorder. This study tested the hypothesis that response frequency is associated with symptom severity in pathological gambling. We tested response frequency among twenty-two pathological gambling sufferers and twenty-one non-problem gamblers on a commercially available slot machine, and screened for pathological gambling symptom severity using the South Oaks Gambling Screen (SOGS). The results showed that pathological gambling sufferers had significantly higher response frequency than non-problem gamblers, and that response frequency was significantly correlated with SOGS symptom severity among pathological gambling sufferers. Finally, binary logistic regression showed that response frequency accurately identified 21 (95.5\%) pathological gambling sufferers and $18(85.7 \%)$ non-problem gamblers. The correlation between response frequency and SOGS may suggest a stronger reinforcement of gambling behavior in individuals with exacerbated pathological gambling symptoms. These findings may have important implications for detecting behaviors underlying pathological gambling.
\end{abstract}

Keywords: pathological gambling, slot machines, symptom severity, response frequency

\section{Introduction}

Slot machines are among the most addictive forms of gambling (Parke \& Griffiths, 2006a; Parke \& Griffiths, 2007), and pathological gambling slot machine players represent the largest group of treatment seekers, accounting for 35\% to 93\% of the population. (Linnet, 2009; Meyer, Hayer, \& Griffiths, 2009; Petry, 2003).

The so-called structural characteristics of slot machines are believed to contribute to the risk of developing pathological gambling (Griffiths, 1999; Parke \& Griffiths, 2006a; Parke \& Griffiths, 2007). Structural characteristics that reinforce gambling behavior are particularly interesting, as they may be associated with pathological gambling. These include frequent small gains and "near misses" (Dixon \& Schreiber, 2004; Kassinove \& Schare, 2001; MacLin, Dixon, Daugherty, \& Small, 2007), big wins (Kassinove \& Schare, 2001; Weatherly, Sauter, \& King, 2004; Wohl \& Enzle, 2003), and manipulation of symbol sequence and contingencies 
(Haw, 2008; Ladouceur \& Sevigny, 2002; Ladouceur \& Sevigny, 2005; Young, Wohl, Matheson, Baumann, \& Anisman, 2008; Zlomke \& Dixon, 2006).

While most studies have investigated slot machine gambling behavior among non-problem gamblers, it is important to identify behavior, which differentiates pathological from non-problem gambling. Studies investigating differences in slot machine gambling behavior show that pathological gamblers play a higher number of games, spend more time gambling, and have a higher response frequency (games / time) than non-problem gamblers (Choliz, 2009; Griffiths, 1994; Linnet, Thomsen, Møller, \& Callesen, 2010). In one study Griffiths (1994) found that regular slot machine players, who played slot machines at least once per week, had a significantly higher response frequency, or play rate (games per minute), than non-regular slot machine players, who played slot machines once a month or less. Similar findings were reported by Linnet et al. (2010) in a study comparing pathological gambling sufferers with non-problem gamblers. These results may suggest an increased reinforcement of gambling behavior in pathological gambling, and that the response frequency may be an important measure in differentiating pathological gambling from non-problem gambling behavior on slot machines. However, no previous studies have investigated whether or not increased response frequency is associated with the severity of pathological gambling symptoms.

This study compared pathological gambling sufferers (PGS) and non-problem gamblers (NPG) playing a commercially available slot machine. We hypothesized that pathological gambling sufferers would have a significantly higher response frequency (i.e., button presses per minute) than non-problem gamblers, and that response frequency would be associated with symptom severity on the South Oaks Gambling Screen (SOGS). Finally, we tested the hypothesis, that pathological gambling sufferers and non-problem gamblers could be classified based on their response frequency.

\section{Methods and Materials}

\subsection{Participants}

Twenty-two pathological gambling sufferers (seven women and 15 men) were recruited for the study. Pathological gambling sufferers were included in the study if they scored five or higher on the South Oaks Gambling Screen (SOGS), were actively gambling, and primarily gambled on slot machines. One self-declared pathological gambler had a SOGS score of four, but was included in the study after assessment with the DSM-IV criteria. Pathological gambling sufferers had to be active gamblers to be included in the study, i.e., having gambled within the past month. The majority of pathological gambling sufferers received treatment at the time of participation. For these participants controlled gambling behavior was the stated or achieved treatment goal. Controlled gambling behavior is a broadly accepted therapeutic goal (Blaszczynski, McConaghy, \& Frankova, 1991; Dowling \& Smith, 2007; Dowling, Smith, \& Thomas, 2009; Ladouceur, 2005).

We recruited twenty-one non-problem gamblers (12 women and nine men) through local newspaper advertisement. To be included participants had to have a SOGS score below two. Non-problem gamblers only played infrequently and with small amounts of money; their gambling frequency could vary from weeks to months and even longer. Pathological gambling sufferers and non-problem gamblers showed no differences in gender distribution, $\chi^{2}(2, \mathrm{~N}=43)=2.79, n s$, but pathological gambling sufferers were significantly older than non-problem gamblers, $F(1,41)=7.26, p=0.01$. The average age of pathological gambling sufferers was 43.8 years $(S D=11.78)$, and was 33.9 years for non-problem gamblers $(S D=13.97)$. The average SOGS score of pathological gambling sufferers was $11.13(S D=3.56)$ and was $0(S D=0.00)$ among non-problem gamblers, $F(1,41)=204.93, p<0.000001$.

We obtained approval for the study from the Danish local ethics committee prior to conducting the study. Participants gave informed consent in writing prior to their participation, and were compensated financially for their time and travel expenses. Afther participation they were debriefed, and they had access to treatment, if needed. We found no increase in gambling symptoms following the experiment in any of the participants. For a full description of the ethical considerations and study design, see Linnet et. al (Linnet, et al., 2010).

\subsection{Procedure}

We used Orientexpressen [the Oriental Express], a popular slot machine in Denmark. The slot machine was provided by Dansk Automatspil A/S, which is the slot machine subsidiary of Danske Spil A/S [Danish Games, Inc].

Before the participants arrived, the slot machine was loaded with 2000 to 2400 credits. The value of one credit was 0.5 DKK (around 0.1 USD) equal to a total amount around 200 USD, which yielded players a total playing time of at least 60 minutes (one participant managed to lose all credits after 50 minutes; the data were recorded 
for this period). If participants ended with more than the preloaded credits, they could keep $10 \%$ of their gains up to a limit of 400 credits (around 35 USD). We used this approach to make the experiment resembled a real life gambling situation. Participants could not lose money from study participation.

The slot machines had an autoplay button, which is a common feature that automatically spins the reels without players pressing the play button (Parke \& Griffiths, 2006b, 2007). The reels only stop when players need to make decisions (e.g., hold or nudge). Gamblers often use this function to play on several machines at the same time. In the study participants were not allowed to use the autoplay function, to ensure maximum attention on the slot machine. After participants completed the experiment, data were retrieved from the slot machine using a hyper-terminal. Sessions were video recorded for documentation purposes.

\subsection{Measures}

The South Oaks Gambling Screen (SOGS). The SOGS is a 20-item self-report questionnaire that assesses lifetime and past year gambling-related difficulties (Lesieur \& Blume, 1993; Lesieur \& Blume, 1987). A SOGS score of five or more suggests a diagnosis of pathological gambling, while a score of 2-4 indicate possible problem gambling..

Time, Response, Reward Return, and Response Frequency. Time spent gambling was measured using a stopwatch from the time participants initiated gambling, until they stopped or were stopped. Time was rounded to the nearest minute. The slot machine counted the total number of response (games) and calculated the Reward Return as the total number of credits won divided by the total number of credits lost (gains / losses). Response frequency was calculated as the total number of responses divided by time spent gambling (response / minute).

\subsection{Statistics}

We used analysis of variance (ANOVA) to measure group differences in response frequency between pathological gambling sufferers and non-problem gamblers. To control for the possible influence of age and Reward Return, we performed a univariate analysis of co-variance (ANCOVA) with response frequency as the dependent variable, group as the fixed factor (pathological gambling sufferers vs. non-problem gamblers), and age and Reward Return as covariates. We further used Pearson's correlation to measure the correlation between response frequency and symptom severity on the SOGS. Finally, we performed a binary logistic regression analysis to determine classification accuracy of response frequency, where group membership (pathological gambling sufferers vs. non-problem gamblers) was the dependent variable and response frequency was the covariate.

\section{Results}

Analysis of variance (ANOVA) showed that pathological gambling sufferers had significantly higher response frequency $(M=22.32, S D=1.60)$ than non-problem gamblers $(M=16.98, S D=3.00), F(1,41)=53.82, p<$ 0.000001 . The results are illustrated in Figure 1. A univariate analysis of covariance confirmed that the differences remained significant when correcting for age and Reward Return, $F(3,39)=18.88, p<0.000001$.

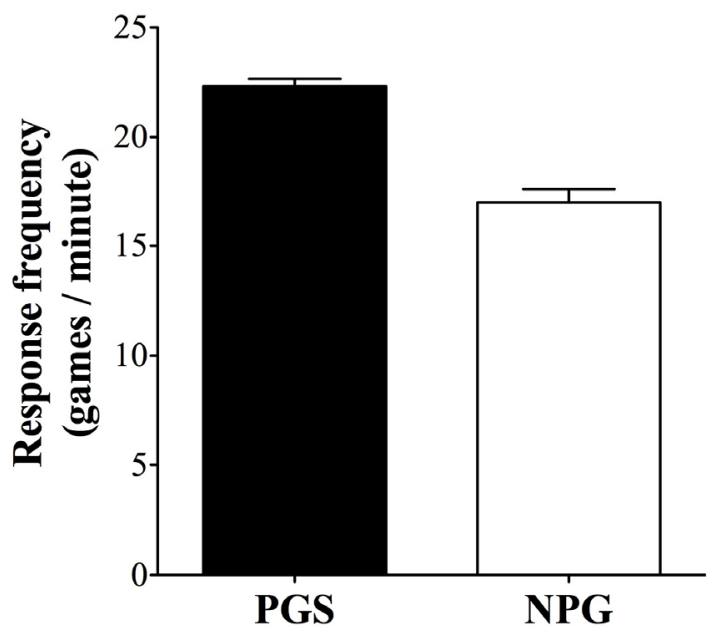

Figure 1. Response frequency in pathological gamblers and non-problem gamblers 
Description: pathological gambling sufferers (PGS, black bar) have significantly higher response frequency than non-problem gamblers (NPG, white bar), $F(1,41)=53.82, p<0.000001$. Error bars indicate Standard Error of Measure (SEM).

Next, we found a highly significant correlation among pathological gambling sufferers between response frequency and symptom severity on the SOGS, $r(22)=0.71, p<0.0005$. The results are illustrated in Figure 2 .

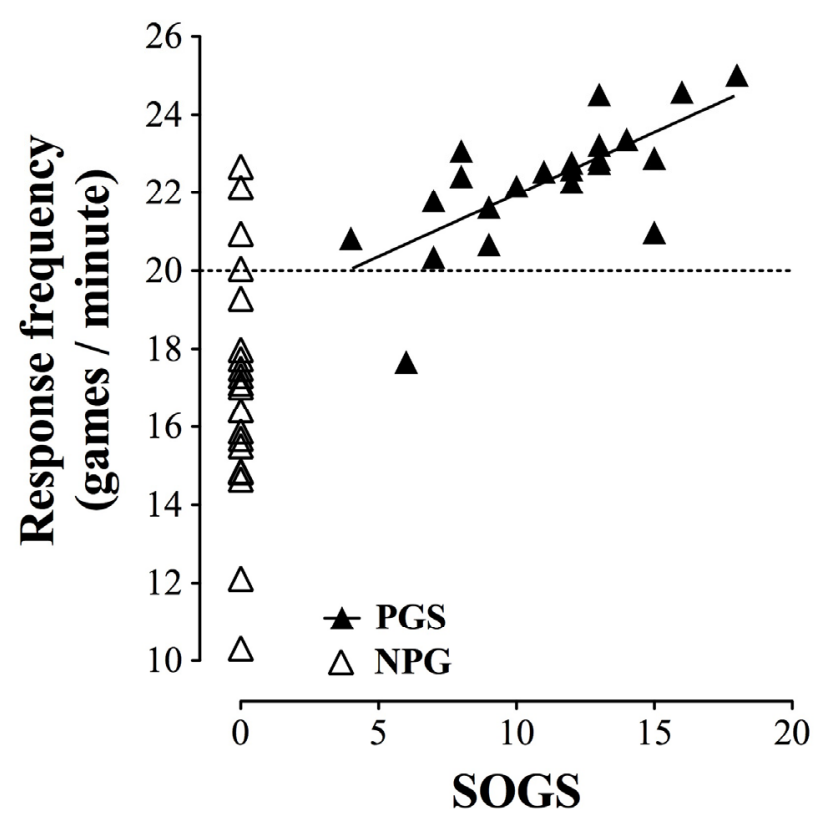

Figure 2. Correlation between SOGS and response frequency

Description: pathological gambling sufferers (PGS, black triangles) show a significant correlation between SOGS symptoms severity and response frequency, $r(22)=0.71, p<0.0005$. The solid line indicates the correlation line. Non-Problem Gamblers do not vary in SOGS scores, and therefore have no correlation.

Finally, we performed a binary logistic regression analysis to determine how accurately response frequency predicted pathological gambling and non-problem gambling behavior. We used pathological gambling sufferers vs. non-problem gamblers as the dependent group variable and response frequency as the covariate.

Response frequency significantly contributed to predicting whether participants were pathological gambling sufferers or non-problem gamblers, $\chi^{2}(1, N=43)=33.54, p<0.000001$, and correctly classified 21 out of 22 (95.5\%) pathological gambling sufferers and 18 out of $21(85.7 \%)$ non-problem gamblers. The overall classification accuracy was $90.7 \%$, and the model accounted for $54.2 \%$ of the variation in response frequency, $R^{2}(41)=0.542$. The Wald coefficient was $12.31(p<0.0005)$ and the odds ratio was 0.41 , which means that for each increase of games per minute, the person was $59 \%$ more likely to be a pathological gambling sufferers. For instance, a person who played 20 games per minute was almost 12 times more likely to be a pathological gambling sufferer than a non-problem gambler $(20 \times 59 \%=1180 \%)$.

The classification accuracy of response frequency can be seen from Figure 2: twenty-one out of 22 pathological gambling sufferers played 20 games or more per minute, while 18 out of 21 non-problem gamblers played fewer than 20 games per minute; three non-problem gamblers were false positives, and one pathological gambling sufferer was a false negative.

\section{Discussion}

This study showed that response frequency was significantly correlated with symptom severity in pathological gambling and accurately classified 21 out of 22 pathological gambling sufferers and 18 out of 21 non-problem 
gamblers. The data may suggest an association between reinforcement of gambling behavior and symptom severity of pathological gambling, and may have important implications for identifying problem gambling behavior.

Pathological gambling sufferers showed a higher response frequency than non-problem gamblers. This is consistent with previous findings in the slot machine gambling literature, where Griffiths (1994) found that regular slot machine players, who played slot machines at least once per week, had a significantly higher response frequency than non-regular slot machine players, who played slot machines once a month or less. The independent replication of findings between the current study and that of Griffiths (1994) suggests that response frequency is an important measure of gambling behavior in pathological gambling. This is consistent with the notion of pathological gambling being a "behavioral addiction" (Holden, 2001; Potenza, 2006).

The increased response frequency on slot machines in pathological gambling is also consistent with the notion of behavioral reinforcement in the disorder (Skinner, 1958, 1963, 1988), and may reflect that in pathological gambling the behavior has been reinforced over time to produce a faster, longer, and more recurrent pattern of behavior than in non-problem gambling. It is also consistent with the notion that the structural characteristics of games often use schedules of reinforcement that optimally reinforce behavior, such as many games per minute (contiguity), high probability of reward close to 50-50 (contingencies), and random or variable rewards. Slot machines in particular exhibit all of these characteristics.

The correlation between response frequency and symptom severity is perhaps the most important finding of the study, because it suggests that patterns of reinforcement have real consequences for the disorder. Pathological gambling sufferers with the highest response frequencies suffer from the most gambling symptoms. This may have implications both for the assessment and treatment of the disorder. From an assessment perspective it may be possible to identify patterns of risky behavior in, for instance, samples of online slot machine gambling. From a treatment perspective it may be possible to use behavior modification to help pathological gambling sufferers who show the strongest patterns of reinforcement.

Finally, Binary logistic regression analysis of response frequency accurately classified 21 out of 22 pathological gambling sufferers and 18 out of 21 non-problem gamblers with an overall classification accuracy of $90.7 \%$. This suggests that response frequency is a valid measure for differentiating pathological gambling sufferers and non-problem gamblers.

From a practical perspective, our data suggest that response frequency is a simple and easy measure suitable for assessment of risky behavior in slot machine gambling. Unlike time spent gambling, number of gambles, and money spent gambling, which are lengthy measures, response frequency can be observed over a matter of minutes, by simply counting the average response frequency over a short period of time. Furthermore, response frequency might have implications for other forms of gambling than slot machine gambling. Response frequency of games such as black jack, roulette, or craps could be measured as the time it takes to make a decision or response, rather than games per minute, as the game frequency in these games are determined by a dealer. However, more research is needed to determine the usefulness of response frequency in relation to assessment of pathological gambling.

While our study suggests that response frequency is an important measure of symptom severity in pathological gambling it also holds limitations. First, while the group differences in response frequency remained highly significant after controlling for age and Reward Return, the findings should be replicated in an age-matched cohort. Second, while our data suggest that response frequency has good sensitivity and specificity of symptom severity in pathological gambling, we note that the SOGS is not a direct measure of pathological gambling. Although the SOGS has shown satisfactory reliability and validity with the diagnostic criteria of pathological gambling (Stinchfield, 2002), a further test of reliability and validity of response frequency in relation to pathological gambling in slot machines should use diagnostic criteria of pathological gambling, such as the DSM-IV criteria. Third, it is not possible from our data to determine whether the increased response frequencies in our cohort was a result of a trait-like vulnerability toward gambling (e.g., some individuals having increased risk of exacerbated symptoms) or a state-like condition (e.g., individuals showing fluctuations in gambling control with periods of increased response frequency and exacerbated symptoms). Future studies should investigate the stability of response frequency over time, and whether or not changes in structural characteristics can modify symptom severity of pathological gambling over time.

In conclusion we find that response frequency is a simple and easy measure which may hold important implications for assessing symptom severity of pathological gambling, and for differentiating pathological gambling and non-problem gambling slot machine behavior. 


\section{References}

Blaszczynski, A., McConaghy, N., \& Frankova, A. (1991). Control Versus Abstinence in the Treatment of Pathological Gambling: A Two to Nine Year Follow-Up. British Journal of Addiction, 86(3), 299-306. http://dx.doi.org/10.1111/j.1360-0443.1991.tb01782.x

Choliz, M. (2009). Experimental Analysis of the Game in Pathological Gamblers: Effect of the Immediacy of the Reward in Slot Machines. Journal of Gambling Studies.

Dixon, J., \& Schreiber, J. E. (2004). Near-Miss Effect on Response Latencies and Win Estimations of Slot Machine Players. The Psychological Record, 54, 335-348.

Dowling, N., \& Smith, D. (2007). Treatment Goal Selection for Female Pathological Gambling: A Comparison of Abstinence and Controlled Gambling. Journal of Gambling Studies, 23(3), 335-345. http://dx.doi.org/10.1007/s10899-007-9064-6

Dowling, N., Smith, D., \& Thomas, T. (2009). A Preliminary Investigation of Abstinence and Controlled Gambling as Self-Selected Goals of Treatment for Female Pathological Gambling. Journal of Gambling Studies, 25(2), 201-214. http://dx.doi.org/10.1007/s10899-009-9116-1

Griffiths, M. (1999). Gambling Technologies: Prospects for Problem Gambling. Journal of Gambling Studies, 15(3), 265-283. http://dx.doi.org/10.1023/A:1023053630588

Griffiths, M. D. (1994). The Role of Cognitive Bias and Skill in Fruit Machine Gambling. British Journal of Psychology, 85(3), 351-369. http://dx.doi.org/10.1111/j.2044-8295.1994.tb02529.x

Haw, J. (2008). The Relationship between Reinforcement and Gaming Machine Choice. Journal of Gambling Studies, 24(1), 55-61. http://dx.doi.org/10.1007/s10899-007-9073-5

Holden, C. (2001). 'Behavioral' Addictions: Do They Exist? Science, 294(5544), 980-982. http://dx.doi.org/10.1126/science.294.5544.980

Kassinove, J. I., \& Schare, M. L. (2001). Effects of the "near Miss" and the "Big Win" on Persistence at Slot Machine Gambling. Psychology of Addictive Behaviors, 15(2), 155-158. http://dx.doi.org/10.1037/0893-164X.15.2.155

Ladouceur, R. (2005). Controlled Gambling for Pathological Gamblers. Journal of Gambling Studies, 21(1), 49-59. http://dx.doi.org/10.1007/s10899-004-1923-9

Ladouceur, R., \& Sevigny, S. (2002). Symbols Presentation Modality as a Determinant of Gambling Behavior. Journal of Psychology, 136(4), 443-448. http://dx.doi.org/10.1080/00223980209604170

Ladouceur, R., \& Sevigny, S. (2005). Structural Characteristics of Video Lotteries: Effects of a Stopping Device on Illusion of Control and Gambling Persistence. Journal of Gambling Studies, 21(2), 117-131. http://dx.doi.org/10.1007/s10899-005-3028-5

Lesieur, H., \& Blume, S. B. (1993). Revising the South Oaks Gambling Screen in Different Settings. Journal of Gambling Studies, 9, 213-223. http://dx.doi.org/10.1007/BF01015919

Lesieur, H. R., \& Blume, S. B. (1987). The South Oaks Gambling Screen (Sogs): A New Instrument for the Identification of Pathological Gamblers. American Journal of Psychiatry, 144(9), 1184-1188.

Linnet, J. (2009). Denmark. In G. Meyer, T. Hayer \& M. Griffiths (Eds.), Problem Gambling in Europe: Challenges, Prevention, and Interventions (p. 333). New York: Springer. http://dx.doi.org/10.1007/978-0-387-09486-1_2

Linnet, J., Thomsen, K. R., Møller, A., \& Callesen, M. B. (2010). Event Frequency, Excitement and Desire to Gamble, among Pathological Gamblers. International Gambling Studies, 10(2), 177-188. http://dx.doi.org/10.1080/14459795.2010.502181

MacLin, O. H., Dixon, M. R., Daugherty, D., \& Small, S. L. (2007). Using a Computer Simulation of Three Slot Machines to Investigate a Gambler's Preference among Varying Densities of near-Miss Alternatives. Behavior Research Methods, 39(2), 237-241. http://dx.doi.org/10.3758/BF03193153

Meyer, G., Hayer, T., \& Griffiths, M. (2009). Problem Gambling in Europe: Challenges, Prevention, and Interventions. New York: Springer.

Parke, J., \& Griffiths, M. (2006a). The Psychology of the Fruit Machine: The Role of Structural Characteristics (Revisited). International Journal of Mental Health and Addiction, 4(2), 151-179. http://dx.doi.org/10.1007/s11469-006-9014-z 
Parke, J., \& Griffiths, M. D. (2006b). The Psychology of the Fruit Machine: The Role of Structural Characteristics (Revisited). International Journal of Mental Health and Addiction, 4, 151-179. http://dx.doi.org/10.1007/s11469-006-9014-z

Parke, J., \& Griffiths, M. D. (2007). The Role of Structural Characteristics in Gambling. In G. Smith, D. Hodgins \& R. Williams (Eds.), Research and Measurement Issues in Gambling Studies (pp. 211-243). New York: Elsevier.

Petry, N. M. (2003). A Comparison of Treatment-Seeking Pathological Gamblers Based on Preferred Gambling Activity. Addiction, 98(5), 645-655. http://dx.doi.org/10.1046/j.1360-0443.2003.00336.x

Potenza, M. N. (2006). Should Addictive Disorders Include Non-Substance-Related Conditions? Addiction, 101(Suppl 1), 142-151. http://dx.doi.org/10.1111/j.1360-0443.2006.01591.x

Skinner, B. F. (1958). Reinforcement Today. American Psychologist, 13(3), 94. http://dx.doi.org/10.1037/h0049039

Skinner, B. F. (1963). Operant Behavior. American Psychologist, 18(8), 94. http://dx.doi.org/10.1037/h0045185

Skinner, B. F. (1988). The Operant Side of Behavior Therapy. Journal of Behavior Therapy and Experimental Psychiatry, 19(3), 171-179. http://dx.doi.org/10.1016/0005-7916(88)90038-9

Stinchfield, R. (2002). Reliability, Validity, and Classification Accuracy of the South Oaks Gambling Screen (Sogs). Addictive Behaviors, 27(1), 1-19. http://dx.doi.org/10.1016/S0306-4603(00)00158-1

Weatherly, J. N., Sauter, J. M., \& King, B. M. (2004). The "Big Win" and Resistance to Extinction When Gambling. Journal of Psychology, 138(6), 495-504. http://dx.doi.org/10.3200/JRLP.138.6.495-504

Wohl, M. J., \& Enzle, M. E. (2003). The Effects of near Wins and near Losses on Losses on Self-Perceived Personal Luck and Subsequent Gambling Behavior. Journal of Experimental Social Psychology, 39(2), 184-191. http://dx.doi.org/10.1016/S0022-1031(02)00525-5

Young, M. M., Wohl, M. J., Matheson, K., Baumann, S., \& Anisman, H. (2008). The Desire to Gamble: The Influence of Outcomes on the Priming Effects of a Gambling Episode. Journal of Gambling Studies, 24(3), 275-293. http://dx.doi.org/10.1007/s10899-008-9093-9

Zlomke, K. R., \& Dixon, M. R. (2006). Modification of Slot-Machine Preferences through the Use of a Conditional Discrimination Paradigm. Journal of Applied Behavior Analysis, 39(3), 351-361. http://dx.doi.org/10.1901/jaba.2006.109-04 